\title{
As implicações da depressão pós-parto na psique do bebê: Considerações da Psicologia Analítica
}

\author{
The implications of postpartum depression in the baby's psyche: Considerations of \\ Analytical Psychology
}

Laura Villares de Freitas ${ }^{[a]}$, Camila Alessandra Scarabe ${ }^{[b]}$, Bárbara Harumi Duque ${ }^{[c]}$

\footnotetext{
${ }^{[a]}$ Professora Doutora do Instituto de Psicologia da Universidade de São Paulo (USP), São Paulo, SP - Brasil, e-mail: lauvfrei@usp.br

${ }^{[b]}$ Mestranda do Instituto de Psicologia da Universidade de São Paulo (USP), São Paulo, SP - Brasil, e-mail: camilascarabel@usp.br

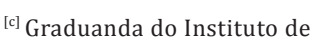
Psicologia da Universidade de São Paulo (USP), São Paulo, SP - Brasil, e-mail: barbara.harumi@gmail.com
}

Recebido: 09/12/2010 Received: 12/09/2010

Aprovado: 30/03/2011 Approved: 03/30/2011

\section{Resumo}

Este artigo aborda, a partir de um estudo teórico, a influência da depressão puerperal na psique do bebê, segundo o referencial da Psicologia Analítica de Carl Gustav Jung. O self e o ego do bebê encontram-se em formação e serão constituídos principalmente por meio da influência da mãe ou de seu substituto. Como a mãe é o primeiro universo da criança e os dois estão em um estado unitário, se a mãe, por estar deprimida, não se mostrar capaz de fornecer os elementos físicos e psíquicos necessários para o bebê desenvolver principalmente o aspecto positivo do arquétipo da Grande Mãe, essa criança crescerá com um self e ego frágeis, além de um sentimento de insegurança perante o mundo, podendo ocorrer, inclusive, severas psicopatologias. A depressão pós-parto pode ser explicada pela constituição de um complexo materno negativo na psique da mãe, necessitando o reconhecimento e o encaminhamento da mulher ao tratamento adequado.

Palavras-chave: Relação mãe-bebê. Depressão pós-parto. Desenvolvimento da psique.

$$
\text { Psicologia Analítica. }
$$

\section{Abstract}

This article, based on a theoretical essay based on Analytical Psychology of Carl Gustav Jung, aims to consider the influence of postpartum depression on the baby's psyche. The baby's ego and self are in formation and are structured mainly through the mother's influence - or her subsitute's. The mother is the child's first universe and constitutes a unitary reality with the child herself. If the depressed mother is not capable of giving the baby the physical and psychical elements he needs in order to develop the positive aspect of the Great Mother archetype, that child will grow with a fragile self and a fragile ego, besides a feeling of insecurity before the world. Consequently, severe psychopathology may develop. Postpartum depression is here considered the consequence of a negative motherly complex in the mother's psyche; it needs to be identified and the woman must receive adequate treatment, as soon as possible.

Keywords: Mother-baby relationship. Postpartum depression. Development of the psyche. Analytical Psychology. 


\section{Introdução}

Muitos estudos têm abordado a influência da depressão pós-parto no desenvolvimento psíquico do bebê, tanto na medicina quanto em diferentes abordagens teóricas da Psicologia. Este artigo tem o objetivo de apresentar e comentar a contribuição que a Psicologia Analítica, criada por Carl Gustav Jung (1961), traz como subsídio teórico nesse campo, aproximando sua compreensão da relação mãe-bebê à questão da depressão pós-parto, buscando sanar em parte a escassez de estudos a esse respeito na Psicologia Analítica. Apesar de Jung ter uma formação médica psiquiátrica, o modelo materialista-biológico não é o predominante em sua visão de mundo (Hauke, 1994), tendo ele desenvolvido um modelo simbólico para considerar as manifestações humanas. Além da contribuição de Jung, este texto traz outros autores da Psicologia Analítica que ajudaram a elucidar o assunto, destacando-se Erich Neumann (1960).

0 presente texto, inicialmente, explica como acontece o desenvolvimento da psique do bebê e a influência nele exercida pela mãe, trazendo conceitos centrais da Psicologia Analítica relativos à dinâmica psicológica, como os de arquétipo e complexo. Em seguida, são apresentadas as principais características do puerpério e da depressão pós-parto, destacando-se o que esta pode implicar na psique do bebê e quais as intervenções necessárias para o tratamento da mãe, de maneira a possibilitar que o bebê sofra o menor impacto possível decorrente da depressão materna.

\section{0 nascimento do bebê}

As estruturas neurológicas do bebê encontram-se em acelerado crescimento desde a vida uterina. Acompanhada do desenvolvimento neurológico, a vida psíquica do bebê também se desdobra. Jung (1926/2002) relata o desenvolvimento da consciência que ocorre na infância, gradual e progressivamente. Nesse campo, dispõe que a psique da criança é extremamente influenciável e dependente da psique dos pais, estabelecendo que existe uma interdependência na relação da criança com seus genitores e o desenvolvimento psíquico.

Neumann (1995), importante teórico da Psicologia Analítica, que trabalhou o tema mãe-bebê e o desenvolvimento de estágios psíquicos na formação da consciência, considera que o bebê nasce ainda não completamente desenvolvido, tanto física quanto psiquicamente, e que a maturação continuará a evoluir num estado de crescimento embrionário pós-uterino, basicamente utilizando-se de recursos proporcionados por seu cuidador primário, geralmente a mãe, ou um substituto dela. Portmann (1958, citado por Jacoby, 2007) chama a atenção para o fato de que o humano recém-nascido não possui uma maturidade própria da espécie nem no seu tipo de movimento, na sua postura corporal, e sequer nos seus métodos de comunicação, sendo maior a influência do meio para continuar o desenvolvimento do que propriamente a dos instintos, ao contrário dos outros animais.

No quesito do fornecimento de subsídios físicos, pode-se dizer que a mãe, ou seu substituto, é responsável por dar ao bebê os cuidados básicos, como o nutrir, o higienizar, o proteger, o acalentar, o aquecer - funções importantes para a sobrevivência do recém-nascido. Todas essas ações respondem a necessidades fisiológicas que o filho manifesta, como, por exemplo, o choro. Importante ressaltar que é todo um conjunto de reações exibidas pela mãe que reúne os componentes necessários para o bom desenvolvimento da criança.

Além da satisfação física, e totalmente imbricado ao seu crescimento corporal, há o desenvolvimento psíquico. Neumann (1995) fala de uma disponibilidade imprescindível de subsídios psíquicos para o término do desenvolvimento do período pós-uterino, já que o neonato tem um self e um ego primitivos, os quais, ao longo do primeiro ano de vida, consolidam-se aos poucos, dependendo da interação com a mãe e da sua possibilidade de acolher a psique do filho. Para a Psicologia Analítica, o ego é o centro da consciência e o self o centro da totalidade da psique, envolvendo o consciente e o inconsciente. 0 ego situa-se entre o self e o mundo, e, nos primeiros anos de vida, ego e self encontram-se em formação, para que o bebê se torne uma individualidade distinta da mãe. Ela é ao mesmo tempo o self, o outro e o mundo externo, preenchendo toda a realidade do bebê, considerada, assim, unitária. A mãe é o primeiro modelo de self e, por conseguinte, se a relação com ela for suprida com mais elementos positivos do que negativos, há a garantia de que aquele bebê adquira um sentimento de segurança básica, que o acompanhará por toda a vida.

A relação da mãe com o bebê, nesse período tão importante para sua evolução, é chamada de relação primal, por causa dos contatos primários que existem 
entre ambos durante todo esse tempo (Neumann, 1995). A partir da dinâmica que se dá nessa fase, são assimilados e interiorizados pelo bebê os elementos fornecidos por seu cuidador, o que desencadeará os processos necessários para a completa formação das estruturas próprias do indivíduo.

\section{A relação primal mãe-bebê}

O bebê nasce com uma apreensão autocentrada do mundo, de modo que não se distingue de todo o resto, vivendo numa unidade biopsíquica. Para a criança, a mãe parece existir para fornecer-lhe gratificação e não como uma pessoa separada e independente dela (Jacoby, 2007). Neumann (2003, p. 31) denomina esse período de urobórico, aludindo à imagem do uroboros:

0 uroboros, a imagem da serpente circular que morde a própria cauda .... é o símbolo do estado psíquico inicial e da situação primordial, em que a consciência e o ego do ser humano ainda são infantis e não desenvolvidos. 0 símbolo da origem e dos opostos nela contidos é o "Grande Círculo" no qual se fundem e interpenetram o positivo e o negativo, o masculino e o feminino, os elementos pertinentes à consciência - e os hostis a ela - e os elementos inconscientes. Nesse sentido, o uroboros também é um símbolo da ausência de diferenciação entre o caos, o inconsciente e a totalidade da psique, a qual será vivenciada pelo ego como estado limítrofe. ... A totalidade urobórica também surge como símbolo dos pais primordiais unidos, os quais se dividem depois na figura do Grande Pai e da Grande Mãe.

A mãe, de modo a fornecer os subsídios necessários ao filho, integra-se nessa unidade biopsíquica, urobórica, criando uma interação com a criança na qual seu self é externalizado e apreendido pelo bebê, que possui um self primitivo. Para o bebê, psique, corpo e mundo externo são indistinguíveis; assim, não se pode dizer de uma percepção das necessidades fisiológicas à parte das manifestações psíquicas, já que seu self está ligado sobretudo às apreensões e percepções do corpo. Tal unidade implica uma não diferenciação entre as necessidades fisiológicas, os atos e as emoções. 0 que acontece nessa fase urobórica, mesmo estando ainda o ego em seus primórdios, deixa marcas em todo o desenvolvimento posterior, constituindo numa fonte de perene nostalgia, que pode ter no adulto um efeito tanto regressivo como progressivo (Neumann, 1995).
Essas ações estão essencialmente ligadas às questões escatológicas da criança, no que pode ser chamado de self corporal, o qual, mesmo sendo estreitamente decorrente de impulsos corporais, não pode ser considerado meramente fisiológico, já que não há distinção entre o físico e o mental.

Aliado a esse self, existe o self relacional, fruto da externalização da mãe, do qual o filho usufrui. A mãe, como responsável pelas satisfações do filho, tais como a alimentação e outros cuidados, também tem como função ser a portadora dos subsídios para o desenvolvimento da psique da criança, a partir do fornecimento de seu self que será a base para que o bebê posteriormente consolide seu self completo.

Importante ressaltar que esta divisão em self corporal e self relacional é meramente didática, dado o caráter unitário em que se encontra a criança nessa fase de seu desenvolvimento, no qual as necessidades fisiológicas urgem e são satisfeitas pela mãe, também numa unidade com o bebê. Dessa forma, o self da mãe é que tem o caráter essencial da relação primal, constituindo o todo da criança e abarcando toda a sua existência, o que confere a essa relação a importância máxima na constituição da psique completa do indivíduo.

Assim, mãe e filho vivem em uma interação, que é dual por englobar dois seres, mas é uma unidade, já que o bebê ainda não possui a capacidade de se diferenciar, nem do mundo nem da mãe. Isso caracteriza uma realidade unitária primal, na qual a criança ainda está contida em sua mãe. Jung comparou o contato da mãe com o bebê à participation mystique expressão cunhada pelo antropólogo Lévy-Bruhl (1939) para indicar um processo de identificação muito intenso e inconsciente. Pode-se dizer que mãe e bebê estão em participation mystique, uma relação estreitamente conjugada, em que se considera que o bebê vive a psique da mãe (Jung, 1931/2007a; Samuels, 1989). A Psicologia Analítica, em termos de desenvolvimento, aponta para um self totalizado, o qual engloba a inteireza da dimensão psíquica do indivíduo. 0 self, como mencionado, é o centro e a totalidade da psique, regulador da vida psicológica como um todo, o "centro da totalidade do ser" (Edinger, 1972, p. 27). Para que se dê um encontro com o self, antes deverá ser formado o ego, centro da consciência. Para a constituição da consciência, o self coordenará a gênese do ego, movimento que é denominado de centroversão (Neumann, 1995). Do self brotará um derivado, que será o ego, encarregado da 
intermediação entre mundo interno e externo. É fundamental para a individualidade que a instância do ego seja formada, já que é a partir dela que a criança começará a reconhecer as pessoas em seu entorno e também a si mesmo, começando a sair da imersão na mãe. A centroversão é um movimento a serviço da personalidade como um todo, tanto na ampliação da consciência quanto na integração da personalidade, complementando-se com o que Neumann (1995) chamou de automorfismo. Esse autor menciona que a centroversão se aplica à relação entre os centros da personalidade e o automorfismo não tanto aos centros psíquicos, mas aos sistemas psíquicos: o consciente e o inconsciente, à relação que estes estabelecem durante toda a vida. 0 automorfismo está relacionado à procura, desde cedo, por um movimento de independência, de ser uma pessoa única, que embasa o processo de individuação.

Para Jung (1930/2000a), tal processo acontece a partir da segunda metade da vida, na meia-idade, quando se dá o que denominou de metanoia. Ele a caracteriza como um período de mudanças, no qual a psique pede uma nova orientação, ocorrendo maior interiorização e geralmente um maior foco no autoconhecimento. Jung supôs que na meia-idade, que ele localiza aproximadamente entre 36 e 40 anos, a pessoa dispõe de um bom acúmulo de experiências vividas, estando já adaptada socialmente e não precisando mais priorizar tanto metas extrovertidas como a busca de estabilidade material, e passa, num retorno a si própria, a buscar outro sentido para sua vida ou, no mínimo, a intensificar o que já escolheu. A partir da metanoia, o foco da centroversão partirá do ego para o self, o sujeito tomando mais consciência de quem é, pelo maior contato com a sua totalidade, e, com isso, caminhando na sua individuação.

Whitmont (2006) comenta a evolução do ego que, esquematicamente, divide em três fases: 1) separação de uma totalidade indiferenciada, iniciando uma diferenciação; 2) grande separação entre ego e self, em que o ego encontra a máxima diferenciação possível; 3) retorno do ego, voltando-se em direção ao self. A primeira etapa ocorre na infância, e Whitmont considera que elementos do meio ambiente, a mãe constituindo um deles, interagem com potenciais existentes, os arquetípicos, para produzir uma primeira personalidade real.

O self da mãe que, no início, é exterior à criança, ao longo do desenvolvimento será internalizado, o que fará com que a criança se torne "ela mesma", separada da mãe. Quando o desenvolvimento vai alcançando seu ponto máximo, há uma tentativa por parte do filho de permanecer ligado à mãe, numa busca de manter a união dual da relação primal, em uma dependência tanto física quanto psíquica. Esse vínculo vai se desfazendo aos poucos, conforme o self materno é internalizado e o ego vai se consolidando e se separando (Neumann, 1995).

Com o ego e o self finalmente mais consolidados, surge entre eles um elo que levará a uma constante interação ao longo da vida psíquica, no qual haverá uma alternância de ciclos entre a união e separação de ambos, a identificação e o rompimento desta. Esse elo é chamado eixo ego- self e ele estará presente em toda a vida psíquica, possibilitando a ampliação da consciência e o desenvolvimento do ego, a partir das tensões por quais passa. 0 prejuízo do eixo traz consequências para a psique e para o ego, o qual corre o risco de perder a relação com sua origem e fundamento, além de tornar-se impedida a interação entre consciente e inconsciente (Neumann, 1995).

Quando a mãe, que participa dessa relação primal, é aquela que atende às necessidades do filho, estando disponível tanto para suas necessidades fisiológicas quanto psíquicas, há a consolidação saudável do ego, então denominado por Neumann (1995) de ego-integral-positivo, o qual consiste num ego capaz de integrar as qualidades, mesmo que negativas, dos mundos interno e externo. Isso ocorre quando a mãe oferece um self compensatório que cuida para que os fatores negativos não sejam em maior intensidade que os positivos. Fatores objetivos como fome, frio e frustração, vividos pelo bebê como vindos do mundo externo, assim como o medo, a raiva e a dor, mais subjetivos, podem ser compensados pela mãe se ela propiciar maior intensidade de experiências positivas, sendo mais a mãe "boa" do que a "má". 0 ego, então, supre-se de confiança, sentindo-se mais seguro do que ameaçado quando invadido por componentes negativos. Por outro lado, quando a mãe não cumpre seus papéis de fornecimento dos elementos necessários para o desenvolvimento da criança, existem grandes consequências negativas, tanto físicas quanto psíquicas. 0 não suprimento dessas demandas do bebê dá a ele o sentimento de insaciedade, de fome e dor, e a mãe passa de Grande Mãe Boa à Mãe Terrível, fazendo desta polaridade do arquétipo, a mais proeminente. A criança ainda não consegue distinguir se a fonte do seu desconforto doloroso está dentro ou 
fora do seu corpo, e, mesmo quando a alimentação e o cuidado físico são perfeitos, falhas na atenção emocional durante o primeiro ano de vida podem gerar distúrbios severos (Jacoby, 2007).

\section{Arquétipos; a Grande Mãe e suas polaridades; os complexos}

Um conceito central na Psicologia Analítica é o de arquétipo. Jung (1916/1998, 1934/2007b) o define como uma estrutura da psique que é comum a todos, não se tratando de uma ideia inata, mas um caminho virtual herdado que rege os modos de pensar e de agir do homem e ressurgindo espontaneamente em qualquer tempo e lugar, sem a influência de uma transmissão externa e sendo determinado apenas quanto à forma e não em relação ao conteúdo. Trata-se de uma base universal, a qual será preenchida pelas experiências individuais, com influência da história e da cultura onde se vive.

Jung (1934/2007b) compara o arquétipo ao sistema axial de um cristal que pré-forma sua estrutura no líquido - mãe, mas não possui uma existência material; é vazio e formal em si, uma possibilidade dada a priori da forma da sua representação. Clarke (1993) argumenta que a tese de Jung não é simples de entender, tendo ela sido formulada de formas diferentes ao longo dos anos. A partir delas, Clarke (1993) apresenta a analogia com o corpo que herdamos e que desenvolve órgãos para a sobrevivência: coração, pulmões, etc. Assim também se dá com o cérebro, que desenvolve não órgãos, mas disposições para comportar-se de certas maneiras favoráveis, como a capacidade de reagir a perigos, procriar e obter alimento. As formas de reagir a tais condições são apreendidas, não como recordações específicas do agente causador - um predador, por exemplo transmitidas pelos genes, mas como uma disposição já presente e inconsciente de comportar-se de determinada forma perante determinadas condições.

Um dos primeiros arquétipos a serem ativados na psique do bebê será o da Grande Mãe. Para a Psicologia Analítica, toda a primeira fase de realidade unitária e da relação primal acontece sob o jugo do arquétipo materno (Jacoby, 2007). Jung considera que, com a influência da mãe real, o ser humano se desenvolve a partir da influência arquetípica, isto é, de como o arquétipo se relaciona com a experiência em sua própria formação. A ideia de "mãe" é um fato psíquico que deve ter sido "criado" por um processo de feedback, de experiências que foram se repetindo no decorrer dos milhões de anos da evolução humana na qual bebês humanos foram dependentes de outras pessoas (Samuels, 1989). E essa estrutura organizadora das primeiras experiências do bebê, Jung (1938/2007c) chamou de arquétipo materno, ou arquétipo da Grande Mãe, considerando como seus atributos: a mágica autoridade do feminino; a sabedoria e a elevação espiritual além da razão; o bondoso, o que cuida, o que sustenta, o que proporciona as condições de crescimento, fertilidade e alimento, o lugar da transformação mágica, do renascimento; o instinto e o impulso favoráveis; o secreto, o oculto, o obscuro, o abissal, o mundo dos mortos, o devorador, sedutor e venenoso, o apavorante e fatal.

No arquétipo da Grande Mãe, podem ser considerados dois polos opostos: um benevolente, envolvendo as funções positivas; e outro, entendido como negativo, possibilitando a manifestação da negligência, do abandono e da proteção em demasia que domina e comprime a individualidade do outro. 0 arquétipo não deve ser compreendido como sendo apenas essas duas polaridades distintas, mas também todos os conteúdos psíquicos que se encontram entre elas e o campo interacional formado. Neumann (2003) traz que é a consciência que opera a separação em polaridades do arquétipo primordial, já que, na situação original inconsciente dos arquétipos, dá-se a união dos opostos, a soma das antíteses. 0 arquétipo materno, portanto, traz em si a questão da ambivalência entre a Mãe Boa e a Mãe Terrível.

0 arquétipo da Grande Mãe formata-se principalmente por meio da interação que se dá na relação primal e pode possuir dois direcionamentos dicotômicos, dependendo de como ocorre a interação mãe-bebê, continuando em construção durante toda a vida. Em todo caso, esse arquétipo também é caracterizado por uma distância da realidade, de um modo mitológico, que dá à mãe características sobre-humanas e poderes absolutos.

A mulher, que é para a criança a provedora de todo subsídio de satisfação, estando presente e saciando suas necessidades, propicia a formação, no filho, de uma imagem de fonte infinita de saciedade, e por isso um caráter divino é atribuído a ela, comumente tendo como imagem uma deusa. Essa mãe disponível faz com que seja mais proeminente 
a polaridade da Mãe Boa no arquétipo da Grande Mãe, com todas as características protetoras e fornecedoras do prazer e da saciação, como fruto da relação primal chamada de positiva (Neumann, 1995). Um símbolo da Grande Mãe Boa é a Virgem Maria, como a mãe acolhedora de todos e confortadora, protetora e acalentadora. Exemplos de imagens simbólicas da Mãe Terrível são a deusa indiana Kali e a bruxa devoradora que aparece na história de "Joãozinho e Maria". Uma imagem ambivalente seria a Mãe Natureza, pois, ao mesmo tempo em que alimenta e dá as condições de sobrevivência na Terra, também é causadora de calamidades naturais, doenças, etc. (Jacoby, 2007).

A polaridade Mãe Terrível do arquétipo da Grande Mãe, ao contrário da Mãe Boa, é aquela indisponível, a causadora da dor e da insaciabilidade, que, se levada ao absoluto, é uma fonte inexistente de recursos. Além da fome e das outras sensações físicas de desconforto, pode se dar uma falta na externalização de seu self para a posterior formação do self completo do bebê e pouca interação emocional proporcionadora de afetos positivos. Tal qualidade de relação primal, por sua vez, é considerada negativa e desencadeia uma série de reações compensatórias em função da não satisfação de suas demandas, gerando um ego negativizado que terá uma centralização muito maior em si. Esse ego tende a se fechar em si próprio, formar barreiras a fim de deixar longe de si tudo o quanto possível, todas as relações que poderiam surgir, o que intensifica a sensação de abandono e solidão sentida a princípio (Neumann, 1995).

Essa situação leva a uma busca de sua independência mais rapidamente do que seria o desenvolvimento normal, o que acaba por privar o ego de seus fundamentos. A indisponibilidade do self da mãe fará com que o self da criança seja formado apenas com uma parte dele, não sendo somado ao self relacional para que o seu seja uma estrutura completa e fortificada. Assim, o ego da criança também ficará fragilizado, já que teve de assumir precocemente sua forma de estrutura completa, sem ter ainda alcançado todo o necessário para a formação saudável.

Como consequência, a polaridade do arquétipo que será mais estabelecida será a da Mãe Terrível, perdendo-se em grande parte o aspecto acolhedor e seguro que haveria de surgir se a dinâmica da interação houvesse sido diferente. Tudo isso faz com que apareça na criança um sentimento primário de culpa, com a convicção inconsciente de que ser bom é ser amado pela mãe, e que, como se sente por ela abandonado, não corresponde a essa expectativa; portanto não é bom, e sim mau. Esse sentimento se refere à fase pré-ego, o que pode levar a um sentimento de sabotagem à própria personalidade ao longo de toda a vida se não for devidamente conscientizado ou assimilado (Neumann, 1995).

Um desenvolvimento negativo da relação primal, como colocado por Neumann (1995), nem sempre é falha ou culpa da mãe pessoal, pois esse estágio inicial é vivido pela influência da Grande Mãe arquetípica. Fatores, como uma ligação emocional insuficiente com o bebê ou a perda da mãe por morte, doença ou separação, são experiências negativas para a criança. Por outro lado, pode não haver ligação com a mãe pessoal. Acompanhada da consideração do fator arquetípico presente na relação com a mãe, Neumann (1995) argumenta que dados como a extensão do dano, o momento em que se deu, sua duração, a maneira como foi compensado pelo meio e fatores constitucionais são elementos importantes para se estimar o prognóstico de uma relação primal prejudicada. Uma compensação da Mãe Boa pode ser feita por meio de um elemento arquetípico impessoal da natureza, tal como uma árvore, um jardim, uma floresta - componentes que façam parte da vida da criança e que lhe proporcionem algum tipo de amparo. Isso é possível caso o dano não tenha ocorrido cedo demais, na fase mais precoce da vida. A integração desses artifícios só ocorre porque a criança apreende o mundo mitologicamente. No entanto, se a experiência da mãe tiver sido negativa, pode ser possível o desencadeamento de uma neurose ou psicose, tendo o ego sido forçado a se desenvolver precoce para suprir a situação de ansiedade, permanecendo falhas e, logo, dificuldades na interlocução eixo ego-self. 0 ego negativizado também pode desencadear uma rigidez acompanhada de muitos mecanismos de defesa, acumulando muitos conteúdos e impulsos no inconsciente. Não conseguindo o ego interagir a eles, esse material, invade a consciência, provocando a irrupção de uma psicose.

Uma relação primal conturbada na infância, de acordo com Jacoby (2007), pode levar os adultos a passarem a vida com uma sensação básica que não há nada em que eles possam confiar, tanto no mundo externo quanto neles mesmos, vivendo algumas vezes um grande sentimento de culpa. Isso conduz à rejeição de sua própria vitalidade interna 
e ao isolamento com desconfiança do ambiente, causando sensação de serem rejeitados e, logo, com dificuldades nos relacionamentos. Os outros são percebidos como partes de uma mãe que os rejeita e devora, já que a Mãe Terrível deixou marcas significativas.

0 desenvolvimento dos arquétipos geralmente não ocorre somente em uma das polaridades, é saudável que a psique transite entre os dois eixos de acordo com a necessidade. É indispensável para todo indivíduo uma parcela de Mãe Terrível, ou seja, vivenciar frustração, dor, dúvida, ansiedade, para conseguir lidar na vida com experiências que não lhe são agradáveis (Allain-Dupré, 2005).

A partir da interação do potencial arquetípico com as experiências, dá-se a formação dos complexos. Eles são conglomerados de imagens com forte carga emocional, reunidos em torno de um núcleo derivado de um arquétipo que atrai para si associações e ideias de teor afetivo. São incompatíveis com as disposições da consciência, portanto inconscientes, e possuem autonomia, levando Jung (1934/2000b) a dizer que nós não temos complexos, mas são eles que nos têm. Enquanto não se possui consciência deles, os complexos podem assaltar a consciência e promover, por exemplo, atos falhos, reações inesperadas e/ou embaraçosas, projeções e sintomas neuróticos. Com diferentes graus de autonomia, os complexos podem se manifestar de distintas formas e, quanto mais distantes da consciência, maior a força com que se manifestam, em função do acúmulo de energia psíquica. Enquanto não for devidamente conscientizada, essa energia permanecerá acumulada e não redistribuída para outros conteúdos. Todavia os complexos não contêm somente aspectos negativos, já que são a própria vida da psique (Jacobi, 1995; Jung, 1934/2000b).

De acordo com Kast (1997), os complexos surgem da interação do bebê/criança com as pessoas de seu relacionamento, por isso a primeira infância é uma etapa sensível para o surgimento dos complexos. Mas eles podem surgir a qualquer momento na vida, não dependendo somente das pessoas reais, como também das atuações da fantasia. Um dos primeiros complexos a se formar na psique é o materno.

Como aspecto básico da psique humana, o complexo materno constituirá um elemento nuclear que pode se manifestar quando as mulheres se tornam mães. Aquelas que tiveram a experiência da Mãe Boa, que conseguiram constituir sua psique de uma forma saudável, com um self completo e um ego bem consolidado, possivelmente passarão por uma gestação normal de forma a manifestar essa polaridade. 0 complexo instaurado em sua psique nesse momento virá à tona no comportamento da mãe, que provavelmente agirá de acordo com sua experiência prévia, mantendo-se disponível ao filho e fornecendo a ele os recursos para seu próprio desenvolvimento.

Em contraposição, as mulheres que passaram pela experiência com o materno sem conseguir os subsídios para a consolidação dos elementos de sua psique de forma saudável, tendo sido gerado um self frágil, incompleto ou um ego assim como mal consolidado, possivelmente terão outra resposta à gestação. A polaridade do arquétipo da Mãe Terrível, tendo construído um complexo materno negativo, pode vir a se manifestar, carregada de energia de forma a gerar uma mãe indisponível a seu filho, repetindo a dinâmica que se deu em seu desenvolvimento. Jung (1909/1997) demonstrou, por meio do experimento de associação de palavras, a tendência à repetição de conteúdos dos complexos ao longo de gerações familiares. Ele criou um teste que consistia em associar a primeira palavra que viesse à mente a cada palavra-estímulo proferida. 0 tempo de resposta era cronometrado e registrado. Jung percebeu que algumas palavras causavam transtornos (como falhas ou demora nas respostas), reações físicas (como suor intenso ou tremores), dentre outros, e que tais palavras estavam interligadas a um intenso conteúdo psíquico inconsciente com significativa carga emocional, que passou então a denominar de complexo. Enquanto não houver alguma elaboração dos complexos, que os torne assimiláveis pela consciência, eles continuarão repercutindo e influenciando inclusive as gerações futuras, pois a psique das crianças é formada por aquilo que constitui, sobremaneira, a vida inconsciente dos pais.

\section{0 puerpério e a depressão pós-parto}

Jung (1912/1999) considera que a depressão pode ser considerada um fenômeno de compensação inconsciente, tendo como objetivo que algum conteúdo subjacente a ela se torne consciente. A depressão causa regressão na energia psíquica - volta ao passado, também levando à introversão - para dentro de si, o mundo interno. 0 anseio dessa volta e dessa interiorização é uma busca pelo mundo materno, 
o primeiro mundo ao qual pertencemos, a unidade urobórica representada pelo aconchego e acolhimento, pela nostalgia, pelo local de refúgio "onde o homem encontra o vaso materno do renascimento, o lugar de germinação, onde a vida pode renovar-se" (Jung, 1912/1999, p. 392-393). No mesmo texto, Jung denomina esse movimento para trás de incesto. No caso da depressão pós-parto, a psique da mulher talvez faça essa regressão ao materno para buscar se encontrar desde sua origem, para poder resgatar e transformar os símbolos que a compõem. No entanto, isso só será possível se a consciência comparecer.

A gravidez representa um período no ciclo vital da mulher no qual ela passa por mudanças significativas nos planos físico, social e psíquico. Fisicamente, caracteriza-se por alterações corporais que têm em vista o crescimento do feto, além das variações hormonais, que acarretam importante efeito psicológico. No plano social, a chegada de um novo membro na família, sendo esta constituída pelos arranjos familiares vigentes atualmente (pai-mãe-primeiro filho; pai-mãe-outros filhos; mãe-filho(os); mãe-outros parentes; entre outros), obriga a reestruturação dessas relações e a redefinição de papéis. Considera-se também o fator econômico, de preocupação em se manter financeiramente mais um membro, principalmente quando a mulher é a única responsável pelas entradas financeiras da família. Psiquicamente, além da influência hormonal, verifica-se a incorporação de novos elementos na identidade da mulher. Tornar-se mãe gera em cada uma sentimentos diferenciados, que são vivenciados de forma intensa e muitas vezes ambivalente, e dependem, entre outros fatores, da sua história de vida, da relação com os pais - especialmente a mãe, do histórico daquela gravidez, das expectativas quanto ao futuro da relação mãe-filho e do seu contexto histórico-social.

A gestação também se apresenta como um momento no qual a mulher pode ter uma possibilidade de amadurecer e desenvolver a sua personalidade. Gallbach (1995, p. 42) expõe que "gravidez e maternidade podem ser vistas como um processo de iniciação, que promove ampliação da consciência ou transformações na personalidade". A possibilidade de transformação após a gravidez, conforme Pattis (2001, p. 78), depende de diversos fatores, podendo não ser "lá tão grande" e não acontecendo espontaneamente de uma hora para outra, mas dando-se, sim, por meio de um processo vagaroso e gradual.
A autora argumenta que na sociedade hodierna, marcada por carreiras agressivas e competitivas, que sugerem livres escolhas e desconfiam de papéis impostos, marginalizando aqueles que dão espaço à estabilidade dos afetos, a maternidade nem sempre acontece como uma passagem iniciática para uma forma adulta de feminilidade.

A mulher quando engravida, mesmo que não esteja especialmente envolvida com a sua gestação, necessita de alguma adaptação em sua vida. Essa mudança não termina com o parto, perdurando durante o puerpério. Após o parto, a mulher vive o luto do corpo gravídico e do bebê dentro de si, necessitando agora ajustar-se a ele e ao seu ritmo, a um bebê real que demanda cuidados e atenção. Uma nova rotina se inicia. Tais transformações em acomodar a condição de ser mãe e cuidar de seu bebê, com a responsabilidade em que isso implica, sofrendo novamente alteração nos níveis hormonais, além do estresse do parto, fazem com que cerca de 20 a 40\% das mulheres apresentem alguma perturbação emocional ou disfunção cognitiva no período pós-parto (Kaplan, Sadock \& Greeb, 2003). Esse momento tem sido designado como "tristeza-pós-parto", ou "pós-parto blues", durando alguns dias. Os sintomas desse quadro são: um estado de abatimento, disforia, choro frequente e dependência exagerada (Kaplan, Sadock \& Greeb, 2003).

Nessa fase aumenta o risco de ocorrerem síndromes psiquiátricas, como no caso da depressão pós-parto. Uma hipótese para a não superação da tristeza-pós-parto é a de que a mulher tenha tido a experiência de uma constituição do materno insuficiente em sua psique. Como ocorre em outras depressões, os fatores psíquicos são de primordial importância para que se desenvolvam tais distúrbios (Silva \& Botti, 2005).

A polaridade Mãe Terrível do arquétipo da Grande Mãe, caso tenha sido a mais desenvolvida na vida da mulher, intensifica-se no momento em que se torna mãe. Segundo Neumann (2003), quando ocorre o nascimento e com ele se conclui a transformação da mulher em mãe, põe-se em atividade uma nova constelação arquetípica, que remodela a vida da mulher até suas camadas mais profundas, facilitando a irrupção desse arquétipo, cuja atração psíquica é muito grande em virtude de sua grande carga energética. 0 ego torna-se incapaz de reagir, e então "sucumbe" e é "tragado" (Neumann, 2003, p. 37). 
Dependendo das imagens arquetípicas maternas predominantes na sua psique, do fato de serem protetoras e nutridoras ou devoradoras, ocorrerá uma confiança natural ou uma desconfiança no ser mãe. Caso tenha sido gerada a desconfiança, essa mãe sentirá uma ansiedade constante nos cuidados ao filho, sempre se indagando "será que estou cuidando bem?", tornando-se a relação mãe-bebê um grande peso, que exaure toda a alegria. Com isso, sente-se sobrecarregada e com ressentimentos em relação ao filho; por conseguinte, dão-se sentimentos de culpa, por achar-se incapaz de amá-lo e por não ser uma boa mãe. 0 complexo materno negativo ativado torna a lida com o bebê tensa e não empática, não irradiando alegria em direção a ele (Jacoby, 2007), e podendo desencadear uma depressão na mãe. Assim, cria-se a condição para o bebê desenvolver o sentimento primário de culpa, a partir da relação primal prejudicada, e repetir a condição que ela mesma vivenciou. 0 complexo, então, passa de geração a geração, conforme Jung (1909/1997) descreveu.

As mulheres cujo complexo materno negativo torna-se proeminente no momento de transição, que é o puerpério, podem não suportar a demanda dos conteúdos que surgem. Quando isso ocorre, então a antes tristeza-pós-parto evolui para a depressão, e os sintomas permanecem por mais de 30 ou 40 dias, caracterizando uma patologia que necessita de tratamento. A cada mil partos, uma a duas mulheres desenvolvem a depressão (Kaplan, Sadock \& Greeb, 2003).

Diversos sintomas são característicos dessa condição: humor deprimido; choro fácil; labilidade afetiva; irritabilidade; perda de interesse pelas atividades habituais; sentimentos de culpa; capacidade de concentração prejudicada; relatos de sentimentos ambivalentes com relação ao bebê e opressão pela responsabilidade de cuidar do filho (Camacho et al., 2006).

Tais sintomas têm em comum a indisponibilidade da mãe com relação ao bebê. A consequência disso será todo o processo descrito anteriormente, levando à formação de uma psique fragilizada no bebê, com um self insuficientemente formado, o que poderá desencadear um ego negativizado e não completamente consolidado.

Byington (2007) assinala que a depressão se articula com as vivências de desapego, em que o ego antigo precisa morrer para dar lugar a um ego novo, transformado. Quanto mais intensa for a necessidade de transformação do self - como nas etapas de transição da vida, maior será o impacto existencial, podendo ser ativada uma depressão considerada normal. Essa depressão adaptativa, a tristeza pós-parto no caso, é um sinalizador do que deve mudar: a integração de um novo papel para a mulher - o ser mãe. Mas quando a mulher não consegue fazer a transição, decorrente dos diversos fatores que podem estar relacionados à representação do materno, ela permanece nela fixada, causando a depressão patológica.

A depressão, conforme Alvarenga (2007), no sentido simbólico, é a melhor expressão da dor da alma que se perdeu de sua própria natureza, ficando num estado de aprisionamento sem conseguir fazer o salto necessário para responder à demanda exigida pelo self de uma nova condição.

\section{Tratamentos}

Para que os efeitos da depressão pós-parto sejam minimizados e a cadeia de transmissão de complexos com teor negativo para as próximas gerações seja encurtada ao máximo, são de extrema importância que se deem certas intervenções. 0 tratamento da depressão pós-parto deve iniciar-se após o período em que se pode distinguir a tristeza pós-parto da depressão, para que não se incorra no erro de tentar tratar um estado que deve desaparecer apenas com a adaptação da mãe a sua nova rotina.

0 acompanhamento farmacológico tem se mostrado essencial, mas de igual ou maior importância é o tratamento psicoterápico que, diferentemente do tratamento de depressões comuns, tem um enfoque maior na diminuição dos sintomas, de forma a minimizar seu impacto, não só na mãe como também no bebê. Fierz (2007) explica que o problema psicológico ligado à depressão não é solucionado somente com drogas, as quais apenas reprimem os sintomas, não levando a um bom prognóstico em longo prazo. Também comenta a atitude necessária ao psicoterapeuta, onde a paciência e o senso de responsabilidade devem proceder do conhecimento de que o paciente deprimido precisa de um curador em quem ele confie, do calor e apoio de um terapeuta que esteja presente para ajudar um ser humano igual a ele. Para isso, é importante observar sem ideias preconcebidas, pensar de maneira descomplicada e ouvir com muito cuidado.

A psicoterapia na depressão pós-parto, além de ter um enfoque diferenciado, também conta com um planejamento especial que engloba, não somente a mãe, mas também sua família e pessoas com quem ela 
tem contato cotidiano, a fim de se construírem novas estruturas para que haja uma melhor adaptação à nova vida de mãe e se deem os cuidados necessários ao bebê.

As mães podem entrar em conflito logo que retornam a seus lares, já que estão com um novo ser sob sua responsabilidade e, por causa das alterações já mencionadas, há uma indisposição generalizada, tanto física quanto psíquica, que causa insegurança, medo, ansiedade, etc. Nesse momento, o acompanhamento de pessoas em quem a mãe confia, seja sua própria mãe, o marido, outro parente ou uma amiga, é de extrema importância para fornecer àquela mulher com anseios certa segurança, de maneira que, aos poucos, ela consiga seguir sua própria rotina com autonomia.

0 tratamento adequado para essa depressão é de suma importância e, para que possa ocorrer no tempo e forma corretos, deve ser identificada o quanto antes. Para tanto, é necessário que os profissionais da saúde que têm contato direto, tanto com o bebê quanto com a mãe, sejam capazes de reconhecer os sintomas e fazer o devido encaminhamento. Muitos dos sintomas podem, sob o olhar errôneo, parecer um simples descuido ou negligência da mãe para com a criança, até mesmo um desinteresse, não sendo reconhecida uma doença que precisa ser tratada e dificultando-se, assim, o acesso ao tratamento.

Para prevenção do estado de depressão, e também para que o diagnóstico seja o mais rápido e preciso possível, os sintomas da tristeza devem ser acompanhados de perto e ter sua evolução estudada. Muitas vezes é necessária uma intervenção profissional, tanto na confirmação do diagnóstico quanto no acolhimento pessoal da paciente.

É preciso que haja uma observação atenta a diversas variáveis, como o fator social, os sintomas e seu surgimento, duração, evolução, dentre outros, para um diagnóstico correto e rápido e o encaminhamento ao tratamento adequado. 0 objetivo é que as consequências da depressão sejam mínimas, tanto para a mãe quanto para o bebê, evitando-se possíveis sequelas posteriores de uma mãe indisponível e uma criança desamparada.

\section{Considerações finais}

A relação que a mãe tem com o seu bebê mostra-se importante para o desenvolvimento psíquico deste, podendo influenciá-lo por toda a sua vida, mesmo sendo a psique dinâmica e podendo escapar a um determinismo fechado. A mãe em si tem seu papel, porém será também importante a percepção daquilo que o bebê tiver apreendido do materno. Ela é o primeiro elemento de constituição da psique, onde o bebê tem seus primeiros contatos com o mundo, vivendo com ela uma participation mystique. Não se trata, portanto, somente da mãe real, mas também da arquetípica. É mais importante o como o bebê percebe as primeiras experiências, integrando em sua psique aspectos de uma Mãe Boa que o alimenta, protege e acaricia, e de uma Mãe Terrível que renega esses atos. Tais experiências irão formando o seu complexo materno.

No entanto, uma mãe ausente, sem envolvimento emocional, que não olha nos olhos do seu filho, provavelmente estará fornecendo mais elementos para a constituição de um complexo materno negativo no bebê. Uma mulher tomada por esse complexo, tendo como núcleo arquetípico a Grande Mãe Terrível, pode desenvolver um quadro depressivo como forma de reação à nova constelação psíquica que o ser mãe lhe suscita, não possuindo recursos suficientes para cuidar do seu bebê, e, com isso, não podendo muni-lo com os elementos físicos e psíquicos necessários a um bom desenvolvimento da nova psique.

Compreender que uma mãe deprimida precisa de atenção profissional para ser cuidadora é importante para encaminhá-la aos tratamentos necessários, pois ela pode não conseguir percebê-los e procurar ajuda por si mesma. 0 apoio das pessoas que a cercam é fundamental para que assumam cuidados do bebê que a mãe não esteja sendo capaz de dispensar.

\section{Referências}

Allain-Dupré, B. (2005). The junguian baby and his mother: Applying Junguian theories to the sources of the psychic life of the newborn child. Revista Junguiana, 23, 128-136

Alvarenga, M. Z. (2007). Depressão: A dor da alma de quem se perdeu de si mesmo. Revista Junguiana, 25, 19-25.

Byington, C. A. B. (2007). A depressão normal e o futuro da civilização: Um estudo da função estruturante da depressão pela psicologia simbólica junguiana. Revista Junguiana, 25, 7-17. 
Camacho, R. S., Cantinelli, F. S., Ribeiro, C. S., Cantilino, A., Gonsales, B. K., Braguittoni, E., et al. (2006). Transtornos psiquiátricos na gestação e no puerpério: Classificação, diagnóstico e tratamento. Revista de Psiquiatria Clínica, 33(2), 92-102.

Clarke, J. J. (1993). Em busca de Jung: Indagações históricas e filosóficas. (R. Jungmann, Trad.). Rio de Janeiro: Ediouro.

Edinger, E. F. (1972). Ego e Arquétipo: Individuação e função psicológica da psique. (A. U. Sobral, Trad.). São Paulo: Cultrix.

Fierz, H. K. (2007). Psiquiatria junguiana. (2a ed. C. G. Duarte, Trad.). São Paulo: Paulus.

Gallbach, M. R. (1995). Sonhos e gravidez: Iniciação à criatividade feminina. São Paulo: Paulus.

Jacobi, J. (1995). Complexo, arquétipo, símbolo: Na psicologia de C. G. Jung. (10a ed. M. Marginic, Trad.). São Paulo: Cultrix.

Jacoby, M. (2007). Saudades do paraíso: Perspectivas psicológicas de um arquétipo. (G. Gerheim, Trad.). São Paulo: Paulus.

Jung, C. G. (1997). A constelação familiar. In C. G. Jung. Estudos experimentais. (L. M. E. Orth, Trad., Obras completas de C. G. Jung, Vol. 2, pp. 478-489). Petrópolis: Vozes. (Originalmente publicado em 1909).

Jung, C. G. (1998). 0 eu e o inconsciente. (13a ed. D. F. Silva, Trad.). Petrópolis: Vozes. (Originalmente publicado em 1916).

Jung, C. G. (1999). Símbolos da transformação. (4a ed. E. Stern, Trad.). Petrópolis: Vozes. (Originalmente publicado em 1912).

Jung, C. G. (2000). As etapas da vida humana. In C. G. Jung. A natureza da psique. (5a ed., Pe Dom M. R. Rocha, Trad., Vol. 8/2, pp. 337-353). Petrópolis: Vozes. (Originalmente publicado em 1930).

Jung, C. G. (2000). Considerações gerais sobre a teoria dos complexos. In C. G. Jung. A natureza da psique. (5a ed. Pe Dom M. R. Rocha, Trad. Vol. 8/2, pp. 27-61). Petrópolis: Vozes. (Originalmente publicado em 1934).

Jung, C. G. (2002). A importância da Psicologia Analítica para a educação. In C. G. Jung. 0 desenvolvimento da personalidade. (8a ed. D. F. Silva, Trad. Vol. 17, pp. 51-66). Petrópolis: Vozes. (Originalmente publicado em 1926).
Jung, C. G. (2007). 0 homem arcaico. In C. G. Jung. Civilização em transição. (3a ed., L. M. E. Orth, Trad. Vol. 10/3, pp. 53-73). Petrópolis: Vozes. (Originalmente publicado em 1931).

Jung, C. G. (2007). Sobre os arquétipos do inconsciente coletivo. In C. G. Jung. Os arquétipos e o inconsciente coletivo. (5a ed. D. M. R. F. Silva \& M. L. Appy, Trad. Vol. 9/1, pp. 15-50). Petrópolis: Vozes. (Originalmente publicado em 1934).

Jung, C. G. (2007). Aspectos psicológicos do arquétipo materno. In C. G. Jung. Os arquétipos e o inconsciente coletivo. (10a ed. D. M .R. F. Silva \& M. L. Appy, Trad. Vol. 9/1, pp. 86-116 ). Petrópolis: Vozes. (Originalmente publicado em 1938).

Hauke, C. (1994). The child: Development, archetype, and analytic practice. Recuperado em 30 jun. 2009, em http://www.rubedo.psc.br/artingle/thechild.htm

Kaplan, H. I., Sadock, B. J., \& Greeb, J. A. (2003). Compêndio de psiquiatria. (7a ed. D. Batista, Trad.). Porto Alegre: Artmed.

Kast, V. (1997). Pais e filhas, mães e filhos: Caminhos para a autoidentidade a partir dos complexos materno e paterno. (M. C. Mota, Trad.) São Paulo: Loyola.

Neumann, E. (1995). A criança: Estrutura e dinâmica da personalidade em desenvolvimento desde o início de sua formação. (10a ed. P. R. Silva, Trad.). São Paulo: Cultrix.

Neumann, E. (2003). A grande mãe: Um estudo fenomenológico da constituição feminina do inconsciente. (4a ed. F. P. Mattos e M. S. M. Netto, Trad.). São Paulo: Cultrix.

Pattis, E. (2001). Aborto: Perda e renovação. (J. P. Neto, Trad.). São Paulo: Paulus.

Samuels, A. (1989). Jung e os pós-junguianos. (E. L. Salm, Trad.) Rio de Janeiro: Imago.

Silva, E. T., \& Botti, N. C. L. (2005). Depressão Puerperal: Uma Revisão de Literatura. Revista Eletrônica de Enfermagem, 7(2), 231-238. Recuperado em 20 abr. 2010, em http://www.revistas.ufg.br/index.php/fen/ article/view/880/1052

Whitmont, E. C. (2006). A busca do símbolo. (14a ed. E. F. Pereira \& K. M. Orberg, Trad.) São Paulo: Cultrix. 
